\title{
Effect of thermomechanical processing defects on fatigue and fracture behaviour of forged magnesium
}

\author{
A. Gryguć, S.B Behravesh, H. Jahed, M. Wells \\ University of Waterloo (Department of Mechanical \& Mechatronics Engineering, 200 University Ave W, \\ Waterloo, ON N2L 3G1, Canada) \\ agryguc@uwaterloo.ca, https://orcid.org/0000-0003-4138-4859 \\ sbbehravesh@uwaterloo.ca,https://orcid.org/0000-0001-6613-2362 \\ hjabed@uwaterloo.ca,https://orcid.org/0000-0002-0270-9254 \\ mawells@uwaterloo.ca, bttps://orcid.org/0000-0001-5789-2773 \\ B. Williams \\ CanmetMATERIALS (Natural Resources Canada, 183 Longwood Road South, Hamilton, ON L8P 0A1, \\ Canada) \\ bruce.williams@canada.ca, bttps://orcid.org/0000-0003-0088-4638
}

R. Gruber, A. Duquett, T. Sparrow, M. Lambrou

Multimatic Engineering (Multimatic Technical Centre, 85 Valleywood Drive, Markham, ON, L3R 5E5, Canada)

rgruber@multimatic.com,aduquett@multimatic.com,tsparrow@multimatic.com,mlambron@multimatic.com

X. Su

Ford Motor Company (Ford Research and Innovation Centre, 2101 Village Road, Dearborn, MI, 48124, USA) xsu1@ford.com, https:/ / orcid.org/0000-0001-8645-1424

ABSTRACT. The microstructural origins of premature fatigue failures were investigated on a variety of forged components manufactured from AZ80 and ZK60 magnesium, both at the test specimen level and the full-scale component level. Both stress and strain-controlled approaches were used to characterize the macroscopically defect-free forged material behaviour as well as with varying levels of defect intensities. The effect of thermomechanical processing defects due to forging of an industrially relevant full-scale component were characterized and quantified using a variety of techniques. The fracture initiation and early crack growth behaviour was deterministically traced

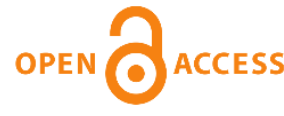

Citation: Gryguć, A., S.K., Behravesh, S.B., Jahed, H., Wells, M., Williams B., Gruber, R., Duquett, A., Sparrow, T., Lambrou, M., Su, X. Effect of Thermomechanical Processing Defects on Fatigue and Fracture Behaviour of Forged Magnesium, Frattura ed Integrità Strutturale, 55 (2021) 213-227.

Received: 27.11.2020

Accepted: 15.12 .2020

Published: 01.01.2021 
back to a combination of various effects having both geometric and microstructural origins, including poor fusion during forging, entrainment of contaminants sub-surface, as well as other inhomogeneities in the thermomechanical processing history.

At the test specimen level, the fracture behaviour under both stress and strain-controlled uniaxial loading was characterized for forged $\mathrm{AZ} 80 \mathrm{Mg}$ and a structure-property relationship was developed. The fracture surface morphology was quantitatively assessed revealing key features which characterize the presence and severity of intrinsic forging defects. A significant degradation in fatigue performance was observed as a result of forging defects accelerating fracture initiation and early crack growth, up to 6 times reduction in life (relative to the defect free material) under constant amplitude fully reversed fatigue loading.

At the full-scale component level, the fatigue and fracture behaviour under combined structural loading was also characterized for a number of ZK60 forged components with varying levels of intrinsic thermomechanical processing defects. A novel in-situ non-contact approach (utilizing Digital-Image Correlation) was used as a screening test to establish the presence of these intrinsic defects and reliably predict their effect on the final fracture behaviour in an accelerated manner compared to conventional methods.

KEYwORDs. Magnesium; Forging; Fatigue; LCF; HCF; Digital Image Correlation
Copyright: (C) 2021 This is an open access article under the terms of the CC-BY 4.0, which permits unrestricted use, distribution, and reproduction in any medium, provided the original author and source are credited.

\section{INTRODUCTION}

$\mathrm{T}$

he successful utilization of lightweight materials in structural applications is an engineering problem which requires a thorough understanding of the service environment of the component to intelligently engineer a manufacturing process suitable for creating high quality and robust solutions for such applications. Typically, $\mathrm{Mg}$ components manufactured using traditional casting methods offer significant reduction in mass compared to other structural metals (due to Mg's low density) however they are generally utilized in applications where they are not significantly load bearing, due to the presence of casting defects which limit strength, ductility and fatigue performance [1]. Generally, wrought forms of magnesium have been renowned for offering improved strength and ductility as they do not suffer from the manufacturing defects and inferior microstructure typical of cast manufacturing methods. Forging $\mathrm{Mg}$ to produce near net shape components can offer substantial performance benefit and facilitate the reliable usage of $\mathrm{Mg}$ in structural fatigue critical components. This has necessitated an immense work towards understanding the complex structural behaviour of forged magnesium components as well as development of the forging process to optimize the resulting material structure, properties and performance.

Recent work on investigating the feasibility of forging have been conducted specifically focusing on AZ80 $\mathrm{Mg}$ as it has good forgeability, and heat-treatability ideal for near net shape of fatigue critical components $[1,2]$. Characterization of the as-forged properties of forged $\mathrm{Mg}$ components in recent years has become 
more widespread in literature. Many studies have focused on characterization of the monotonic structural properties of forged AZ80 and ZK60 Mg, in open die forgings [3-5] as well as for closed die forged components such as wheels [6-8], aerospace components [5,8-12], and finally, automotive structural components [13-24]. In general, the main focus of these studies was the feasibility of achieving adequate material flow to produce the desired forged shape, whilst characterizing the resulting microstructure and quasi-static material properties. Chen et al. utilized a two-step die-forging process of extruded AZ80 Mg at $350^{\circ} \mathrm{C}$ to produce a complex aerospace component where the second forging step aided in removing underfilling and fold defects that persisted after the first step [10]. Matsumoto et al. conducted forging combined with backwards extrusion of ZK60 Mg to produce simple components with small rib features and found that ZK60 has a high propensity for the surface to oxidize at temperatures greater than $400^{\circ} \mathrm{C}$, and shear cracks would develop at temperatures below $200^{\circ} \mathrm{C}$, however at $300^{\circ} \mathrm{C}$ they were able to forge a component which was free of macroscopic defects. Several recent works by Gryguć et al. have investigated varying the processing parameters of $\mathrm{Mg}$ forging with the specific objective of improving the strength, fatigue performance, and improving the homogeneity of properties throughout the forging $[3,4,19-23,25-$ 27]. Despite this, there has been little to no work done on developing a link between the fatigue response and nature of the failure morphology to the forging defects present in an $\mathrm{Mg}$ component produced via an industrially representative forging process. This work aims to investigate the effects of thermomechanical processing defects on the fatigue behaviour of forged $\mathrm{Mg}$ components by using the material properties extracted from the small-scale specimens which are free of macroscopic defects from within the forged component whilst comparing and contrasting them with the component level behaviour under in-service loading in a realistic forged component with varying levels of defect intensities.
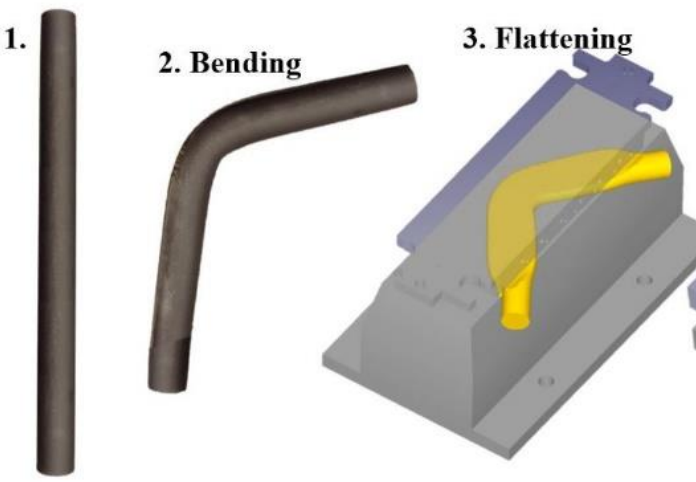

4. Die Forging

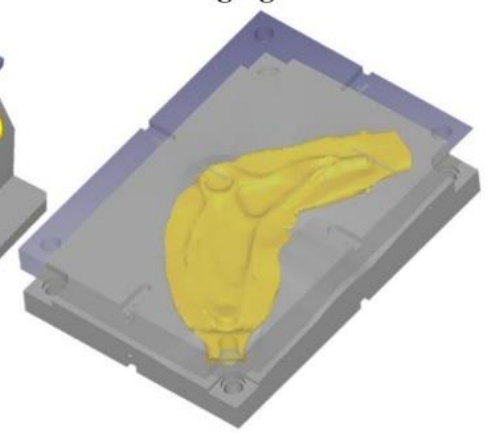

\section{Machining}

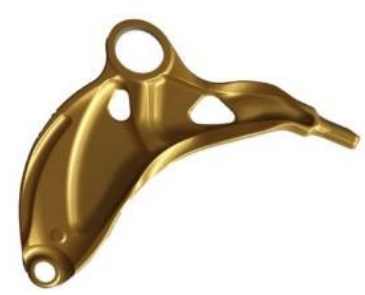

Figure 1: Plan view of extruded billet during different stages of forging operation to achieve final component (prior to machining of the flash). Steps 3 and 4 show simulation predictions with transparent top-dies to allow visualization of the forged shape following each step.

\section{EXPERIMENTAL SETUP}

he material used in this investigation was commercially-available AZ80 Mg extruded billet (Al: 8.0 $\pm 0.2 \%$, with other elements composition as per ASTM B91-12 standard) as well as ZK60 Mg extruded billet (Zn: 5.8\%, Zr: 0.61\%. The AZ80 and ZK60 materials were received from Luxfer MEL technologies both in the as-fabricated condition. The dimension of the extruded billet were a diameter of $63.5 \mathrm{~mm}$ and a length of $1000 \mathrm{~mm}$. The forging was conducted at CanmetMATERIALS (Hamilton, Canada) using the billets which were cut down to a length of $680 \mathrm{~mm}$. The billets were pre-bent at elevated temperature of $300^{\circ} \mathrm{C}$ to an angle of $108^{\circ}$ in a pre-forming step using a mandrel bender to achieve the rough general shape and curvature of the component (step 2 in Fig. 1). They then heated again to $300^{\circ} \mathrm{C}$ for 3 hours prior to flattening (step 3 ) to redistribute the material in preparation for the single step closed-die 
forging. The flattened billet was then heated to the target forging temperature $\left(300^{\circ} \mathrm{C}-450^{\circ} \mathrm{C}\right)$ for 1.5 hours (to allow any thermal gradients to decay) and isothermally forged using a 1500-ton hydraulic press using heated upper and lower dies with a complex internal geometry representing an automotive suspension lower control arm (step 4). Graphite lubricate was used on the die and billet to reduce friction, sticking and promote material flow. The orientation of the billet to the press was such that the radial direction was along the direction of the press stroke (i.e. the direction of forging was along the radial direction of the billet). Forging was carried out in a single step at a displacement rate of $2.1-4.2 \mathrm{~mm} / \mathrm{sec}$. Following die-forging the component was removed from the die and air cooled to room temperature. A final machining operation (step 5) facilitates the removal of excess material (flash) from the forging and ensures interfacing surface features requiring high dimensional accuracy have a smooth machined surface. All of the full-scale components which were investigated in this study were tested in the as-machined condition, with no additional post treatments or surface coatings.

Tensile monotonic and fatigue test samples were utilized with geometries according to Roostaei et al. [28] and a $4 \mathrm{~mm}$ thickness, these were machined from various locations throughout closed die forged component. There were 18 test samples that were extracted from 18 different locations throughout the closed die forging (see Fig. 2), all with varying thermomechanical histories. The test samples had a nominal surface finish of $\mathrm{Ra} \leq 0.2 \mu \mathrm{m}$ within the gauge section, however in practice the actual roughness was substantially less, around $0.05 \mu \mathrm{m}$ These samples were later utilized for quasi-static and cyclic (stress \& straincontrolled) testing. The quasi-static tensile tests were performed according to ASTM standard E8/E8M15a using an MTS 810 Servo-Hydraulic test machine operating in displacement control mode with a displacement rate of $1 \mathrm{~mm} / \mathrm{min}$. Strain measurement was accomplished using a GOM ARAMIS 3D 5MP DIC system which passively functioned to measure the average axial strain on the surface of the gauge section of the sample throughout the duration of the test. The fatigue tests were performed as per ASTM E466-15 for the stress-controlled, and ASTM E606 for strain-controlled, in an ambient environment using an MTS 810 Servo-Hydraulic test machine operating in stress control mode at a frequency range of $0.5 \mathrm{~Hz}$ to $60 \mathrm{~Hz}$ depending on the load amplitude to maintain an approximately consistent loading rate between all tests. The strain was measured throughout the first 10,000 cycles using an MTS 632.26 extensometer with an 8 - $\mathrm{mm}$ gauge and travel of \pm 1.2 - $\mathrm{mm}$ until stabilization of the cyclic hysteresis loop was achieved. The fatigue tests were conducted at a zero mean stress for stress-controlled (i.e., $R_{L}=-1$, fully reversed stress cycle) or zero mean strain (for strain-controlled) and stress amplitudes of between $140 \mathrm{MPa}$ and $180 \mathrm{MPa}$ and total strain amplitudes between $0.35 \%$ to $1.4 \%$. The failure criteria for the specimen level tests were considered to be final rupture of the specimen gauge section.

Full-scale testing of the die-forged component with a load history which is representative of the in-service fatigue loads was carried out on a bi-axial load apparatus that simulated the longitudinal (LD) and lateral loading (TD) on the component and a single load application point. The component was constrained at two other locations using rubber bushings similar to the way it is installed and supported in service. In comparison with the polished fatigue test specimens, the full-scale die-forged component had an asfabricated surface roughness which was substantially higher than the polished lab-specimens (although still quite low for typical as-forged surfaces); ranging from $0.6 \leq \mathrm{Ra} \leq 1.3 \mu \mathrm{m}$ for $\mathrm{AZ} 80 \mathrm{Mg}$, and $0.5 \leq \mathrm{Ra} \leq 1.7 \mu \mathrm{m}$ for ZK60 Mg. The loading was carried out as per specification by the Automotive Original Equipment Manufacturer (OEM), with alternate blocks of high and low amplitude loads with some non-zero mean stress. This differs from the fully reversed constant amplitude loading which was done in the laboratory test-specimen level experiments that were used to characterize the material properties, as the full-scale test is meant to understand the holistic fatigue performance of the component within the physical system under representative service loads. The fatigue loading was bi-axial in nature with various proportionality ratios and phase angles between longitudinal and lateral loading axes, this induced varying levels of multiaxiality and bending stresses in the critical areas of the component (such as the DIC screening region). The tests were carried out in an ambient environment with cooling air supplied to stabilize the temperature of the rubber bushings which supported the component as large amounts of repeated deformation can cause 
softening and damage to the rubber due to strain related internal heat generation. The frequency of loading employed was $1 \mathrm{~Hz}$ under force control for the fatigue loading, then screening cycles were performed at a much lower frequency (quasi-static) at regular intervals which were nominally 10\%, 50\%, 100\%, 150\% of the "target fatigue life" defined by the component specifications. These slower screening cycles were utilized to monitor critical areas within the component that had either known or likely thermomechanical processing defects, this was accomplished via non-contact, in-situ strain field monitoring using digital image correlation (DIC). Once a macroscopic crack nucleation was detected via the DIC screening technique, the screening interval increment was generally increased to $10 \%$ of target live intervals to provide more temporal resolution to monitor the crack growth behaviour. The failure criteria for the component level tests were considered to be $>40 \mathrm{~mm}$ of longitudinal displacement at peak load which would generally correlate to a large crack in the region of interest, normally between $2-40 \mathrm{~mm}$ in length. Important to note is that this failure criteria was intentionally selected to aid in monitoring the growth of fatigue cracks related to thermomechanical processing defects and differs from that of the specification of the Automotive OEM for the component. If the support bushings became worn or broken this was not considered a failure of the component, they were replaced with new items and the fatigue loading continued as to find the structural failure within the magnesium die-forged suspension component. Investigation of the fracture surfaces of both the specimen and component level samples was accomplished utilizing SEM techniques (FEI Quanta FEG 250 with EDX), as well as quantitative light optical microscopy (LOM) using a Keyence VHX 6000 $\& 7000$.
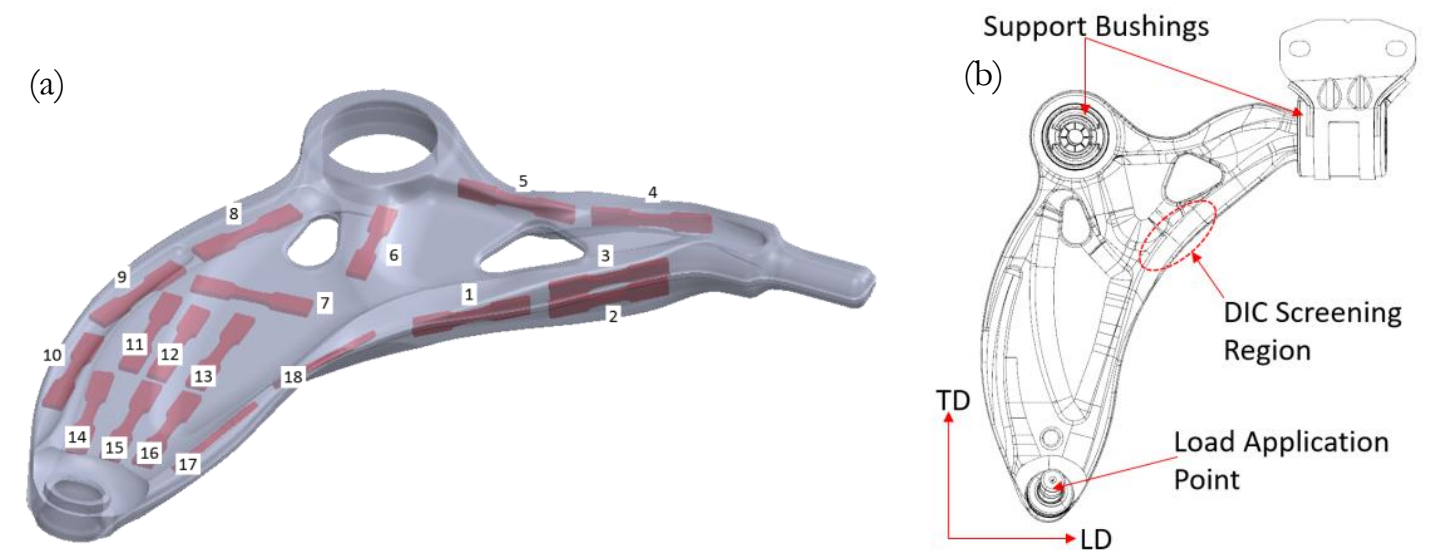

Figure 2: Schematics of die-forged components highlighting (a) Sample extraction locations and (b) loading/screening schematic during full-scale component level fatigue testing. LD denotes the longitudinal direction of loading and TD transverse direction.

\section{RESULTS AND DISCUSSION}

$\mathrm{D}$ ue to the complex nature of the forged component investigated here (both from a geometry, process variable evolution and service loading point of view), the nature of the thermomechanical defects were traced using multi-modal approach. These various strategies included, identifying failure initiation locations, and investigating the fracture surface morphology and defect constituents (both geometric and particulate) surrounding the location of initiation and early crack growth. Furthermore, these observations were both qualitatively and quantitatively assessed to compare and contrast AZ80 and ZK60 $\mathrm{Mg}$ forged components under traditional fully reversed fatigue loading in a laboratory style test with "dogbone" specimens extracted from the component in the vicinity of the critical locations, as well as the full-scale testing of the component under the representative service loading. The rationale behind the employed approach is to identify in similar forged components the relative effect of thermomechanical 
defects by contrasting the material behaviour with and without the presence of a defect, and connecting it with the component level failure mode to determine if premature failure was driven by the presence of a defect. A novel non-contact approach was used to monitor the surface of the critical areas of the component during the fatigue loading to visualize the morphology of the defect, and quantify its severity and evolution over time to the threshold where it causes structural failure. Digital image correlation was used to monitor the strain field in the critical area during specific intervals of the fatigue loading, and trace its evolution over time to understand the influence of thermomechanical defects on the nucleation and early growth behaviour of fatigue cracks. Although using DIC techniques to measure the strain field surrounding the crack tip in notched specimens has been done by other researchers for magnesium alloys [29,30], in this study, conventional techniques for crack detection such as optical microscopy, x-ray scanning, and die-penetrant were not effective at locating the presence of an incipient crack or initial defect, as they generally are done with the component in a resting state under no load [31,32]. Furthermore, with the exception of x-ray, these conventional techniques are not typically effective for detection of subsurface defects as they require some evidence of the defect to have nucleated at the surface. As can be seen in Fig. 3, even in the very first tensile reversal, the employed DIC technique was able to detect saturation of strain in the plane which would eventually become the fatigue fracture surface, as the subsurface defect within the forged material effectively acted like an incipient crack when observed in-situ under the tensile load reversal. The component highlighted in the aforementioned figure had no visible forging defects such as underfill, cold-shuts or surface cracking in this critical location as can be seen in Fig. 3a [1,33]. These types of in-situ screening tests can provide industrially relevant quantitative feedback to the forging developers to optimize the process parameters and reduce the detrimental effects of incipient defects caused by the forging process. The local accumulation of strain at the surface is well known to be caused by the stress concentration effect which acts to locally amplify the stresses and strains in the area surrounding the subsurface incipient crack which in the case of Fig. $3 \mathrm{~b}$, are $\sim 4$ times larger than the structural strains in the surrounding area of the gross cross section.
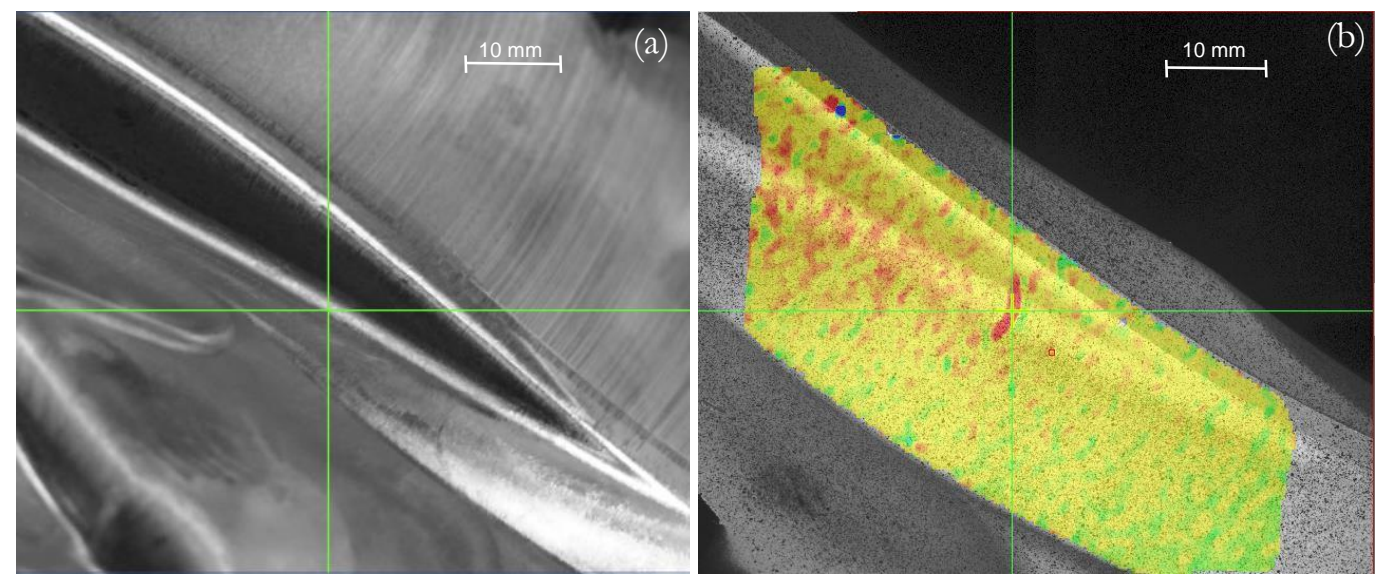

Figure 3: Critical location in $\mathrm{ZK} 60 \mathrm{Mg}$ component forged at $300^{\circ} \mathrm{C}$ highlighting area of thermomechanical defect, shown in Fig. 2b as "DIC screening region" (a) macro image of component in unloaded state following step 4 (die forging) prior to machining and (b) in-situ DIC under peak tensile load at first reversal of fatigue loading. The location of the green crosshairs highlights the peak strain of $\varepsilon_{\mathrm{MAX}}=0.8 \%$ observed using in-situ DIC at peak tensile load during first reversal.

\section{Fracture behaviour in laboratory test-specimens under fully reversed loading}

Fully reversed stress-controlled, and strain-controlled fatigue testing was done on conventional dog-bone type test-specimens which were extracted from various locations within the as-forged component. The nature of the crack initiation and fracture morphology were investigated to better understand if any 
significant thermomechanical defects were present and their level of contribution on the nucleation, growth and final failure of the material. Shiozawa et al. investigated the dependency of stress amplitude level on the fracture surface morphology of extruded AZ80 Mg, and saw virtually no difference in the surface roughness in the area immediately surrounding the fatigue crack initiation (FCI) as well the fatigue crack propagation (FCP) zones for samples which were tested at both high and low stress amplitudes [34]. They also observed cracks which initiated at the surface with a singular origin on the sample, which is largely similar to those types of failures which are presented in this current study. The lack of dependence of the surface roughness surrounding the initiation zone on the nominal stress amplitude forms the basis of comparison for highlighting the presence of incipient defects near the FCI. More specifically, since the local stresses at the FCI will be amplified due to the stress concentration factor (SCF) superimposed by the incipient crack like defect, we can still compare the surface roughness to distinguish material which was fractured due to the applied fatigue load, from material which was poorly fused from a cold-shut type defect which behaves like an incipient crack. Fig. 4 illustrates the macroscopic morphology of the fracture surface and topological features with roughness assessment using quantitative LOM for a laboratory fatigue test specimen with geometry as per Gryguć et al [21]. This specimen was extracted from location \#8 within the forged component which was free from these aforementioned macroscopic cold-shut/poor fusion defects, and then subsequently underwent fully reversed strain-controlled fatigue testing with a strain amplitude of $\varepsilon_{\mathrm{A}}=$ $0.8 \%$ and failed at 568 cycles. The stabilized peak and valley stresses were $+285 \mathrm{MPa}$ and $-230 \mathrm{MPa}$ respecitvely. It can be observed in Fig. 4a that the FCI location is in the upper right-hand corner of the image, and that progresses diagonally across the sample cross section. Furthermore, the roughness observed in the direction parallel with the crack growth direction highlighted by the red line in Fig. $4 a$, is $R_{a}=0.74 \mu \mathrm{m}$ which corresponds well with that which was observed by Shiozawa et al in the crack growth zones (yellow zone in Fig. 4b) in the fracture surface in AZ80 extrusion [34]. Fig. 4c highlights the roughness profile of the location denoted by the red line in Fig. $4 \mathrm{a}$, large macroscopic fatigue striations can be seen which represent large unstable jumps in the crack growth at those locations within the FCP zone. This roughness profile can be thought of as a normalized surface profile to account for curvature or inclination of the surface in order to highlight the features of the surface topography on a more detailed level.
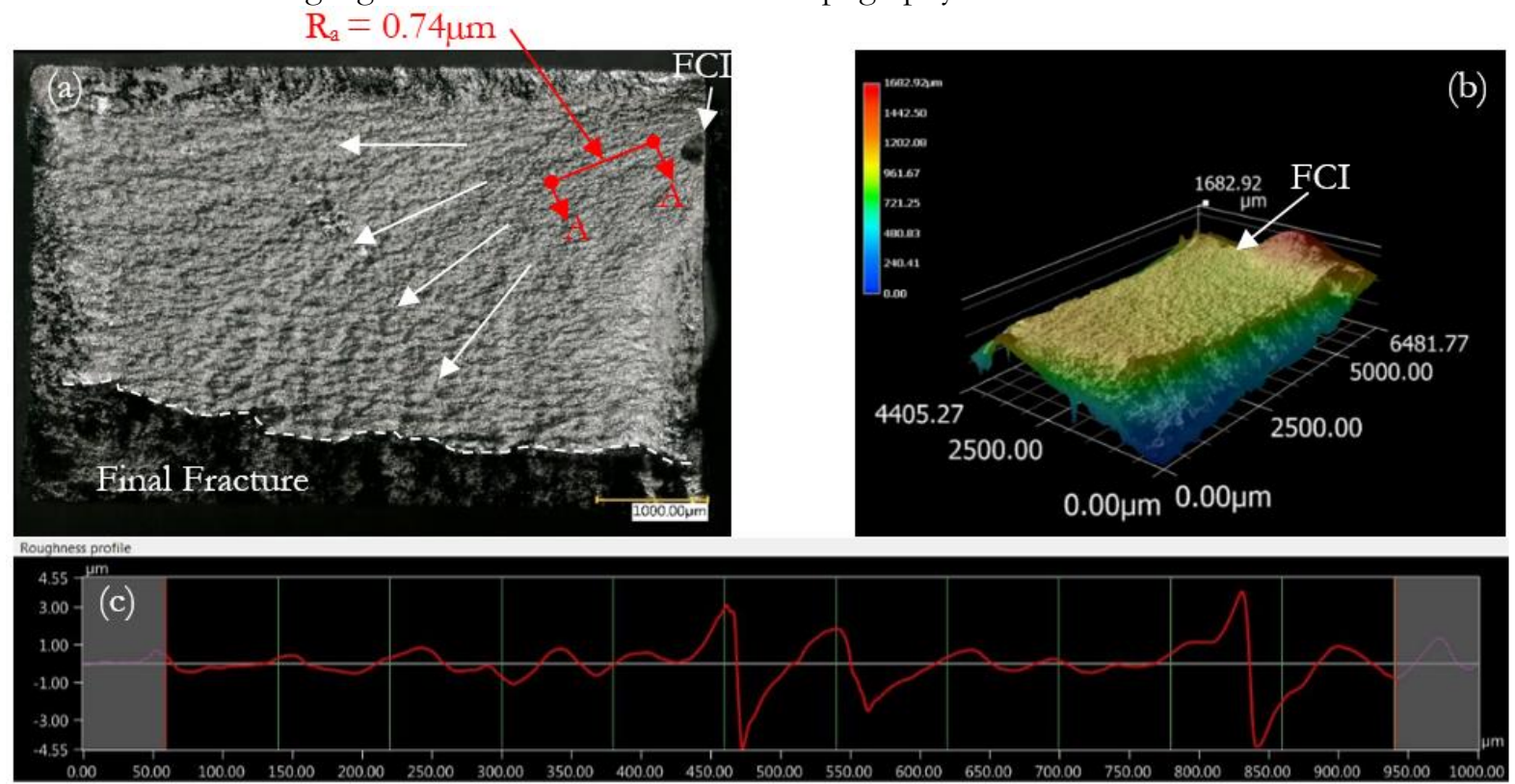

Figure 4: Fracture surface of strain-controlled fatigue test specimen extracted from location \#8 of AZ80 Mg forged component (a) macroscopic view of fracture surface, (b) quantative LOM of fracture surface to highlitght macroscopic topological features (c) roughness profile of section $\mathrm{A}$ in the fatigue crack growth area of fracture surface with an average surface roughness of $\mathrm{R}_{\mathrm{a}}=0.74$. 
Fig. 5 illustrates the fracture surface of a fatigue specimen extracted from location \#3 of the forged component of which underwent stress-controlled fatigue testing at a fully-reversed stress amplitude of 160 $\mathrm{MPa}$. The specimen gauge section was intentionally located in the region within the component which had a high propensity for cold-shut/poor fusion defects, in order to benchmark the material behaviour relative to other areas within the component with similar thermomechanical history but without these persistent forging defects. This location was identified to also be the critical area of concern in fatigue testing of the full-scale component, and consistently showed evidence of these persistent forging defects originating from a fold line in forging flash fronts that was partially/poorly fused together during the die forging process. This defect will then act as an incipient crack if there is not favourable local temperature and pressure to facilitate fusion of this aforementioned fold line during the die-forging process. Fig. 5b illustrates a detailed view of the secondary cracks in the vicinity of the FCI. The proportion of cross sectional area for the final fracture region is $\sim 41 \%$, for reference the bulk forging properties (free of forging defects) spatially vary depending on the local thermomechanical history, and thus a range of $\sigma_{\text {UTS }}$ between $\sim 328-364 \mathrm{MPa}$ is typical.
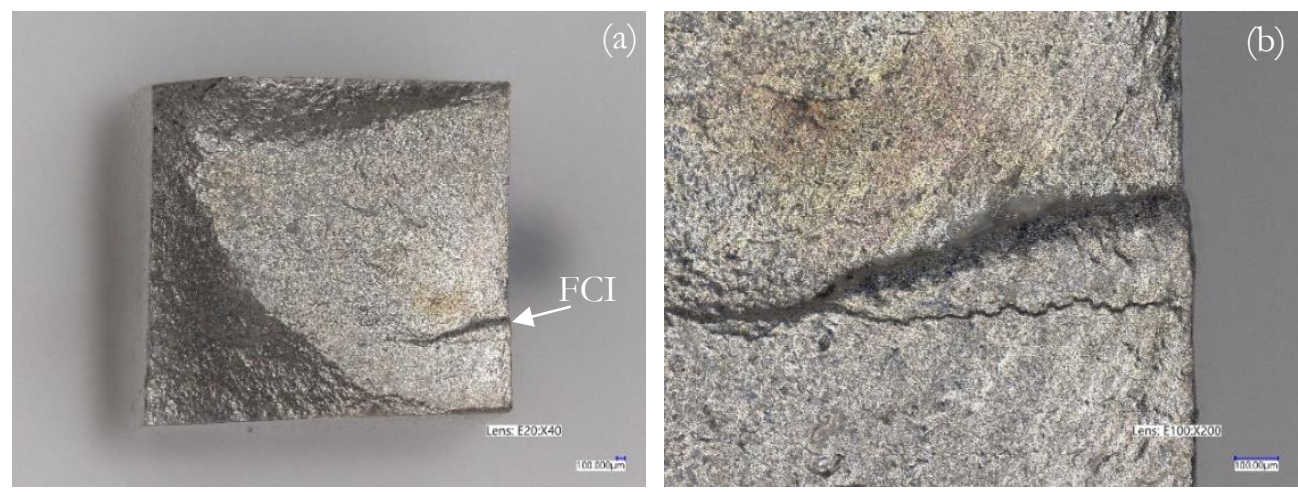

Figure 5: Fracture surface of stress-controlled fatigue test specimen extracted from location \#3 of an AZ80 Mg forged component (forged at $300^{\circ} \mathrm{C}, \sigma_{\mathrm{AMP}}=160 \mathrm{MPa}$, failure after 46,428 cycles) (a) macroscopic view of fracture surface and (b) detailed view of secondary crack at FCI location.
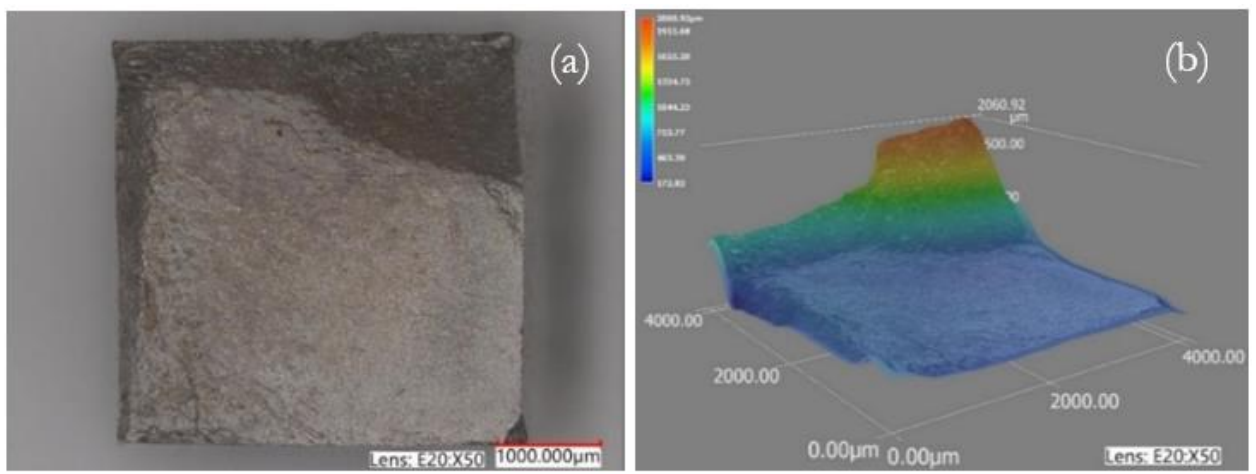

Figure 6: Fracture surface of stress-controlled fatigue test specimen extracted from location \#13 of an AZ80 Mg forged component (forged at $300^{\circ} \mathrm{C}, \sigma_{\mathrm{AMP}}=160 \mathrm{MPa}$, failure after 282,092 cycles).

Fig. 6 illustrates the fracture surface of a fatigue specimen extracted from location \#13 of the forged component, which is away from the area which had persistent forging defects. The fully reversed fatigue stress amplitude was also $160 \mathrm{MPa}$, however, this sample exhibited a life which was over 6 times longer than that from location \#3. Despite location \#3 and \#13 having slightly varying thermomechanical histories, this variation in life between the two locations clearly illustrates the detrimental effect that the forging defects have on the fatigue properties of the forged material. Furthermore, the authors are cognizant of the 
stochastic nature of fatigue, however this observation is supported by the final fracture region being $~ 26 \%$ in the sample extracted from location \#13, which agrees well with the degraded strength (and associated fatigue performance) observed in location \#3 in the vicinity of the defect. Mackie et al. observed a similar detrimental effect to the strength of direct-chill cast AZ80 Mg when comparing defect free material to those with high intermetallic particle density and entrained oxide films under monotonic loading [35].
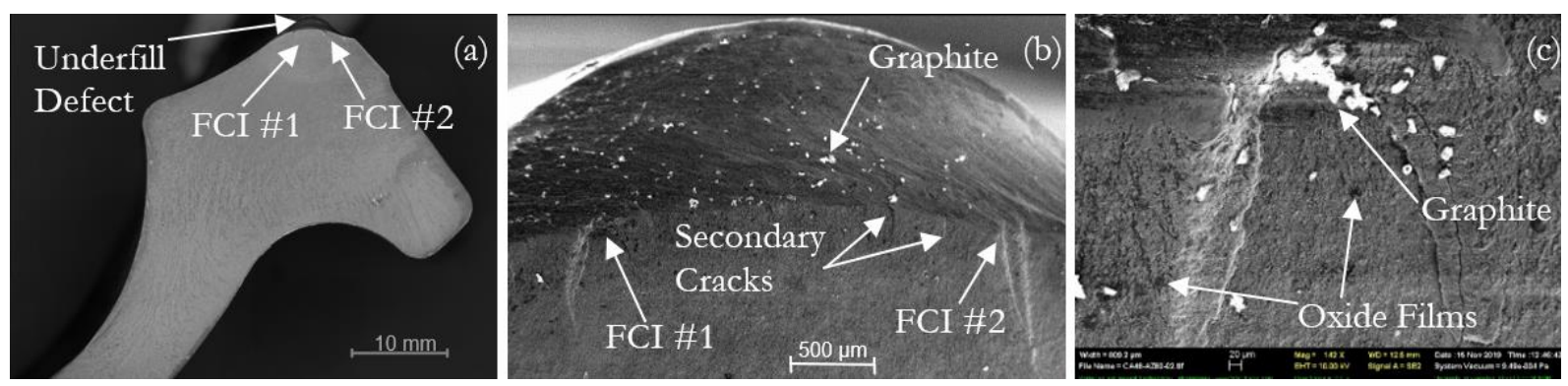

Figure 7: Fracture surface of AZ80 Mg forged component after full-scale service loading, with failure occurring at 41\% of target durability lifespan. (a) global fracture surface morphology (b) SEM image of the FCI location (c) detailed SEM image of area surrounding the left hand side FCI \#1 location, highlighting oxides and graphite particles that were entrained subsurface during the forging process.

\section{Fracture behaviour in full-scale component under representative service loading}

A multi-scale characterization approach was utilized to develop a microstructural based link between the fatigue and fracture behaviour of forged magnesium laboratory style fatigue test specimens and representative durability testing of full-scale components. The transition between the continuum and component length scales helps to illustrate the combined effects of size, loading protocol, and loading multiaxiality has on the detrimental impact of microstructural defects on the fatigue response of forged magnesium alloy. The representative service loading is composed of alternate blocks (low and high intensity) of constant amplitude non-zero mean bi-axial loading which induce an equivalent fatigue damage to the durability requirement of the component in service. In the test apparatus, the load input and constraints imposed on the component replicate the physical configuration in service, and as such, the alternate low and high intensity lateral and longitudinal loading blocks result in structurally representative deformation modes which induce varying levels of stress multiaxiality depending upon the location within the component. As there is no "gauge section" of the sample as in the typical fatigue test specimen, at the component level, critical location which is prone to fatigue failure results from a combination of factors, firstly, the high levels of local cyclic stresses, which are exacerbated by local stress concentrations induced by geometric features in the component and thermomechanical forging defects. Fig. 7 highlights the fracture surface of a forged AZ80 full-scale component which exhibited failure due to a forging defect at $41 \%$ of the target durability lifespan. Fig. 7b, illustrates an SEM image of the FCI location highlighting an underfill defect and entrained graphite particles which were utilized as a lubricant during the forging process. The graphite particles are easily visible in the SEM image as they are of high contrast due to their conductive nature and the employed imaging technique. The majority of these graphite particles range in size from 20$60 \mu \mathrm{m}$, with evidence of several being entrained into the material exposed on the fracture surface following failure. The underfill defect is also clearly visible with a depth of $\sim 1.5 \mathrm{~mm}$ with the fracture initation occuring in the plane of the deepest part of the defect (where the local stress concentration is maximum). Fig. $7 \mathrm{c}$ is an SEM image highlighting the area surrounding the left hand side FCI location, further illustrating the abundance of large graphite particles that were entrained subsurface during the forging process. Furthermore, evidence of several oxide films were identified as well from their chemical compoisition as well as their lack of contrast and their film like morphology. The presence of these large graphite particles in the immediate vicinity of the FCI forms the second portion of the justification for the observed failure location, as these brittle particles act as local stress concentrations within the poorly fused mateiral for which 
fatigue cracks will nucleate more easily. This agrees well with Mackie et al. whom investigated the effect of oxide films on DC cast AZ80 Mg alloy and found them to have an embrittling effect, with approximatley half the ductility of the defect free material, which is largely similar to the influence of graphite particles which act to embrittle the material in the current study [35]. Further supporting these observations, the second FCI location displayed similar initiation morphology, also with large and numerous graphite particles in the vicinity of the crack nucleation location. The size and morphology of these graphite particles as well as their subsurface distribtution can have a profound effect upon the smaller secondary cracks, several of which can be observed in Fig. 7b between the FCI\#1 and \#2. The location of these secondary cracks also corresponded with graphite particle contamination, albeit smaller in size and less numerous.
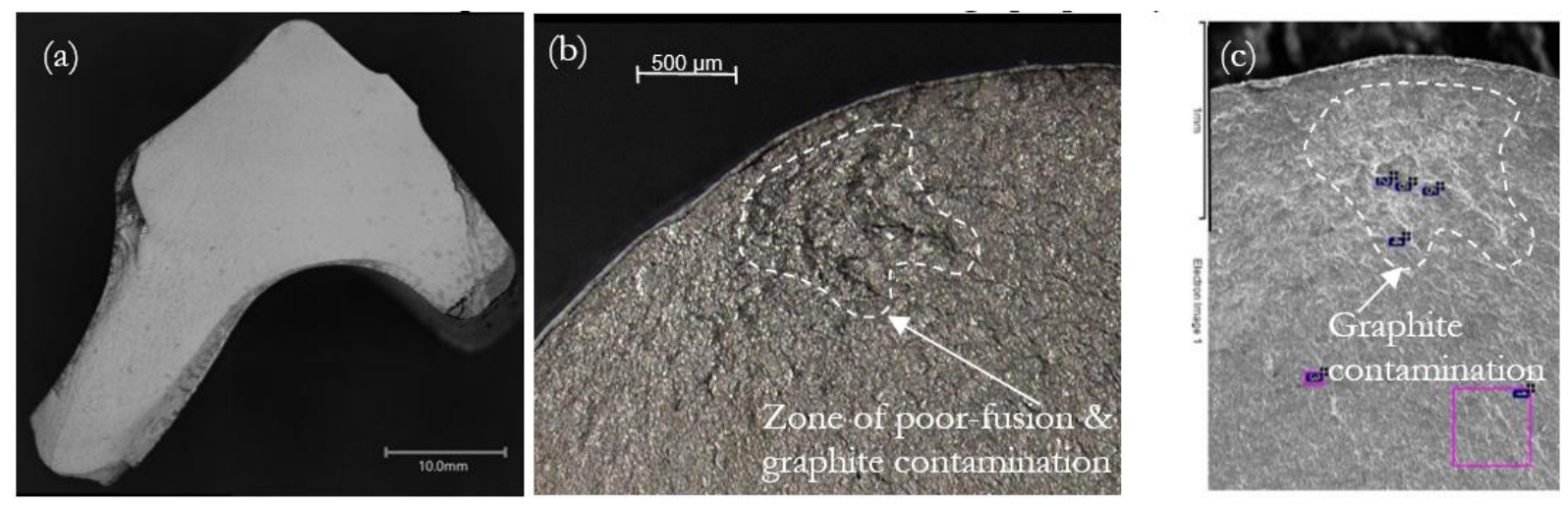

Figure 8: Optical and SEM images of the fracture surface of ZK60 Mg forged component after full-scale service loading, with failure occurring at 184\% of target durability lifespan highlighting (a) global fracture surface morphology (b) optical image of the FCI location, and (c) SEM image of the same FCI location with EDS chemistry.

Similar observations can be made on another forged $\mathrm{Mg}$ component, which underwent identical fatigue loading, yet had a different forging defect intensity at the critical location. Fig. 8 illustrates the fracture surface morphology of a ZK60 Mg forged component after a failure which occurred at 184\% of the target durability lifespan. The forging defect intensity, which can be described as a combination of the geometric defects (such as underfill) and thermomechanical defects (such as cold-shut/poor fusion) and embrittling particulate contamination is less significant in this particular forged component (in comparison with the previous forging discussed in Fig. 7). Although the two Mg alloys are different (AZ80 vs. ZK60), their defect free fatigue properties are very similar (for the processing conditions of these two forgings which were both $300^{\circ} \mathrm{C}$ and a rate of $2.1-4.2 \mathrm{~mm} / \mathrm{sec}$ ) $[21,22,36]$. The component with a lower forging defect intensity exhibited almost a $4.5 x$ longer life than the one with a higher defect intensity. This agrees well with the degradation in life factor of $\sim 6 \mathrm{x}$ that was observed in the laboratory style specimens which were contrasting defect free to high intensity forging defect fatigue response. At the larger scale of the full-scale component the comparison is between a high and low intensity forging defect, and thus the observation of a degradation factor that is slightly lower is reasonable. Furthermore, the laboratory style specimens which underwent fully reversed strain-controlled uniaxial loading nominally had little to no strain gradient within the gauge section of the sample, compared to the complex three dimensional shape and variable amplitude multiaxial loading at the full-scale component level. Fig. 8b illustrates a detailed optical image of the FCI location, which shows no evidence of a geometric underfill defect, multiple FCI sites or secondary cracking at the surface. It does however, show evidence of thermomechanical poor fusion defects located $\sim 0.5 \mathrm{~mm}$ subsurface. Further investigation under SEM with EDS highlighted that dispersed throughout the poor fusion defect is a large zone of graphite contamination with entrained graphite particles (similar to those in Fig. 7c) albeit smaller in size and entrained deeper subsurface. This type of defect morphology, although still acts to degrade fatigue performance, is not as detrimental as the high intensity forging defects previously discussed. Interesting to note however is the location of fatigue crack initiation is in the same general 
location within the component as the high intensity forging defect case, however in-situ screening measurements which monitored the nucleation and growth of these defect induced cracks revealed multiple critical locations which had high propensity for failure.

Fig. 9 illustrates the evolution of axial strain fields at the surface of a ZK60 Mg component that was forged at $300^{\circ} \mathrm{C}$ at peak tensile load, which were computed using Digital Image Correlation (DIC) with the axial direction being parallel to the direction of crack opening. Fig. 9a illustrates the strain field at the very first tensile reversal peak of the representative service loading, with no obvious incipient cracks being evident. The evolution of the strain field can be observed through Fig. 9b and Fig. 9c which were captured at the peak of the tensile reversal at $50 \%$ and $150 \%$ of the target life respectively. The location of peak axial strain is denoted by the green crosshairs shown in each corresponding figure. The peak axial strain at this location was computed in the axis parallel with the crack opening direction and has magnitudes of (a) $\varepsilon_{\mathrm{AXIAL}}=0.39 \%$ in the first reversal, (b) $\varepsilon_{\mathrm{AXIAL}}=0.48 \%$ at $50 \%$ of the target life, and (c) $\varepsilon_{\mathrm{AXIAL}}=1.96 \%$ at $150 \%$ of the target life.

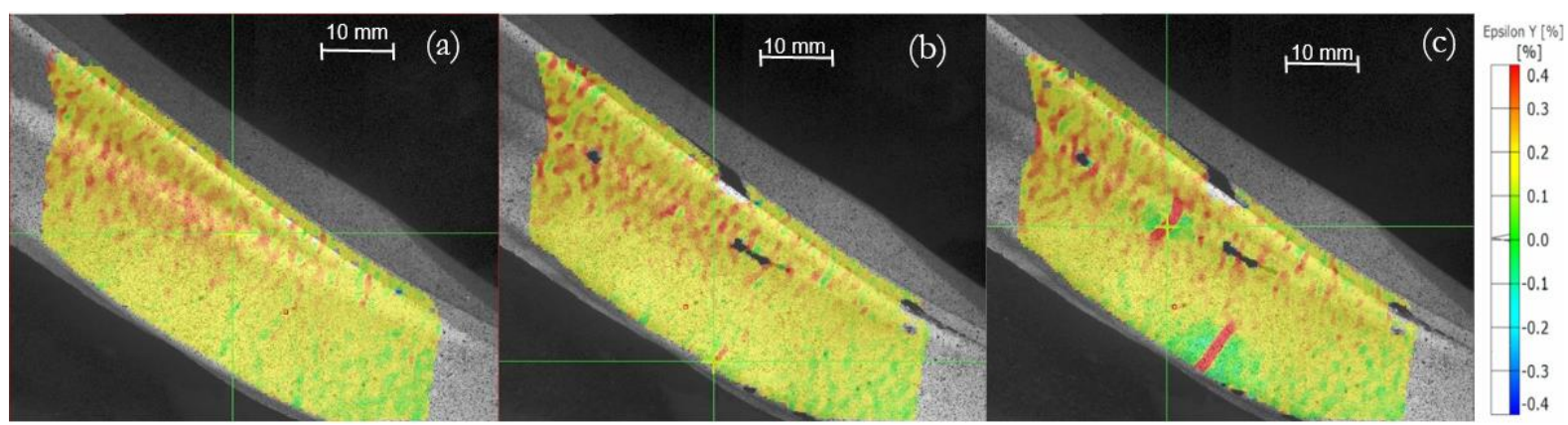

Figure 9: Axial strain fields computed using Digital Image Correlation (DIC) in the direction of crack opening in a ZK60 Mg component that was forged at $300^{\circ} \mathrm{C}$ under peak tensile load at (a) $1^{\text {st }}$ cycle and (b) $50 \%$ and (c) $150 \%$ of target life during variable amplitude fatigue testing (representative service loading). The location peak strain in the image is denoted by the green cross-hairs in the image. The scale for axial strain is shown on the right with areas with high tensile strain being shown in red and those with high compressive strain being shown in blue.

Figs. $\mathrm{b}$ and $\mathrm{c}$ show evidence of nucleation and growth of these incipient crack defects with strain accumulating along planes that are perpendicular to the bending induced alternating axial strains which form a significant portion of the cyclic damage mechanism for forged $\mathrm{Mg}$ alloys under multiaxial loading $[21,22,36]$. These incipient crack defects manifest themselves as a local accumulation of strain (indicated by the red needle like elliptical zones) at the surface of the component during the peak of the tensile reversal as that is where the largest distance from the neutral axis of bending occurs. This high strain gradient local to this strain accumulation is further amplified by the fact that the resistance of the subsurface incipient crack to tensile stresses is lower than the surrounding material. The major axis of these incipient cracks increases in length over time as the strain field evolves throughout the duration of the fatigue loading as the forging defect amplifies the local stresses and accelerates the cyclic damage mechanism. This major axis of the red needle like elliptical zones can be roughly correlated to the fatigue crack size within the material, its morphology can also be linked to the shape and evolution of the crack surface. This can be observed in Fig. $9 \mathrm{~b}$ which was the first screening interval which the first crack was detected (at $50 \%$ of the target life), where evidence of incipient crack nucleation is shown in the region denoted by the green crosshairs, with no other "physically small" cracks being observed in this critical location in that particular life range [37]. However, Fig. 9c illustrates how the growth of the crack evolves at $150 \%$ of the target life, as well as a new incipient crack which has developed. Within the context of this novel imaging technique, the fatigue indicator parameter (FIP) can be considered to be the presence of this inhomogeneous strain accumulation (representing the nucleation of an incipient crack) within the critical region of interest. The usefulness of this FIP which has been facilitated by the employed DIC imaging technique is the fact that it is a non- 
contact in-situ parameter that can be measured with good sensitivity to cracks induced by both surface and subsurface defects, something that is not readily feasible with other more conventional crack monitoring techniques such as optical microscopy, x-ray scanning, and die-penetrant. Furthermore, the efficacy of this technique is further enhanced as the measurement is conducted at peak tension, which effectively amplifies the strain gradient in the area affected by the notch induced stress concentration. Currently, computed tomography (CT) has been effective at characterizing the size and morphology of both internal defects as well as deformation activity at very high resolutions within $\mathrm{Mg}$ material, however it is not practical for the larger than specimen level length scales associated with the component level test investigated here [35,38,39]. Furthermore, the local stress state within the critical area of the full-scale component can be difficult to replicate in an in-situ CT measurement as scaling down the specimen size poses practical constraints in both the loading, as well as size effect induced defect related stress concentrations on the macroscopic fatigue response. The eventual failure which was illustrated in the fracture surface in Fig. 8 occurred in the $2^{\text {nd }}$ location of incipient crack nucleation, identified by the green crosshairs in Fig. 9c. The employed technique was effective in identifying the nucleation and propagation of incipient cracks within a $\mathrm{Mg}$ component which originated from forging defects that were both very high intensity (as shown in Fig. 3) as well as comparatively low intensity (Fig. 8, Fig. 9) even when the origin of the forging defect is subsurface. The FIP of inhomogeneous strain accumulation proved to be effective in identifying these critical locations and tracing their evolution over time through periodic screening intervals of the full-scale component. This technique is quite effective in identifying physically small cracks at the component length scale, as well as assessing the influence of forging defects upon the crack incubation and microstructurally small crack growth stages in $\mathrm{Mg}$ alloys [37].

\section{CONCLUSIONS}

$\mathrm{T}$ he microstructural origins of premature fatigue failures were investigated on a variety of forged components manufactured from AZ80 and ZK60 magnesium, both at the test specimen level and the full-scale system level. The effect of thermomechanical processing defects due to forging of a physical full-scale component were characterized and quantified using a variety of techniques. At the fullscale component level, the fatigue and fracture behaviour under combined structural loading was also characterized for a number of forged components with varying levels of intrinsic thermomechanical processing defects. A multi-scale characterization approach was utilized to develop a microstructural based link between the fatigue and fracture behaviour of forged magnesium laboratory style fatigue test specimens and representative durability testing of full-scale components. Through combination of qualitative and quantitative observations regarding the fracture behaviour of forged $\mathrm{Mg}$ components an effective fatigue indicator parameter (FIP) was identified. Based on these results the following conclusions can be drawn:

1. For the $\mathrm{Mg}$ forging investigated here, the forging defect intensity can be described as a combination of the geometric defects (such as underfill) and thermomechanical defects (such as cold-shut/poor fusion) and embrittling particulate contamination all of which are detrimental to fatigue life.

2. In fully reversed stress-controlled fatigue of forged AZ80 Mg at the specimen length scale, the presence of a high intensity forging defect had the detrimental effect of reducing the fatigue life by more than 6 times at a stress amplitude of $160 \mathrm{MPa}$ relative to the defect free material.

3. At the component level, the failure was governed by intrinsic forging defects which were present to some degree in all of the investigated components. In multiaxial representative service loading at the component length scale, the difference in life between a ZK60 Mg component with a high and (comparatively) low intensity forging defect was found to be $\sim 4.5$ times, with the defects that were larger and closer in proximity to the surface being more detrimental to fatigue. 
4. A novel in-situ non-contact approach (utilizing Digital-Image Correlation) was utilized to detect presence of inhomogeneous strain accumulation forming the basis for a FIP which was effective in identifying both surface and subsurface forging defects in $\mathrm{Mg}$ components.

5. Under multiaxial representative service loading, the nucleation and growth of incipient cracks induced by forging defects are characterized by local strain accumulating along planes that are perpendicular to the principal strains which dominate the cyclic damage mechanism in forged AZ80 and ZK60 Mg components.

\section{ACKNOWLEDGEMENTS}

$\mathrm{T}$ he financial support of the Natural Sciences and Engineering Research Council of Canada (NSERC) through the Automotive Partnership Canada (APC) under APCPJ 459269-13 grant with contributions from Multimatic Technical Centre, Ford Motor Company, and Centerline Windsor are acknowledged. The authors would also like to acknowledge J. McKinley from CanmetMATERIALS for forging trials.

\section{REFERENCES}

[1] Papenberg, N.P., Gneiger, S., Weißensteiner, I., Uggowitzer, P.J., Pogatscher, S. (2020). Mg-alloys for forging applications-A review, Materials (Basel)., 13(4), pp. 1-63, DOI: 10.3390/ma13040985.

[2] Ovsyannikov, B. V. (2007). Die-Forged Disks for Automobile Wheels in Magnesium Alloys. Magnesium: Proceedings ofthe 7th International Conference Magnesium Alloys and their Application, pp. 352-356.

[3] Gryguc, A., Shaha, S.K., Behravesh, S.B., Jahed, H., Wells, M., Williams, B., Su, X. (2017). Monotonic and cyclic behaviour of cast and cast-forged AZ80 Mg, Int. J. Fatigue, 104, pp. 136-149, DOI: $10.1016 /$ j.ijfatigue.2017.06.038.

[4] Gryguc, A., Shaha, S.K., Behravesh, S.B., Jahed, H., Wells, M., Williams, B. (2020). Improvement of Fatigue Properties of AZ31B Extruded Magnesium Alloy through Forging, Frat. Ed Integrita Strutt., 53(SI: Virtual Conference on Structural Integrity), pp. 152-165, DOI: 10.3221/IGF-ESIS.53.13.

[5] He, H., Huang, S., Yi, Y., Guo, W. (2017). Simulation and experimental research on isothermal forging with semi-closed die and multi-stage-change speed of large AZ80 magnesium alloy support beam, J. Mater. Process. Technol., 246, pp. 198-204, DOI: 10.1016/j.jmatprotec.2017.03.015.

[6] Wang, Q., Zhang, Z.M., Zhang, X., Yu, J.M. (2008). Precision forging technologies for magnesium alloy bracket and wheel, Trans. Nonferrous Met. Soc. China (English Ed., 18(SPEC. ISSUE 1), pp. s205s208, DOI: 10.1016/S1003-6326(10)60203-8.

[7] Zhao, X., Gao, P., Zhang, Z., Wang, Q., Yan, F. (2019). Fatigue characteristics of the extruded AZ80 automotive wheel, Int. J. Fatigue, 132, pp. 105393, DOI: 10.1016/j.ijfatigue.2019.105393.

[8] Yuan, L., Zhao, Z., Shi, W., Xu, F., Shan, D. (2015). Isothermal forming of the large-size AZ80A magnesium alloy forging with high mechanical properties, Int. J. Adv. Manuf. Technol., 78(9-12), pp. 2037-47, DOI: 10.1007/s00170-014-6780-9.

[9] Su, Z., Wan, L., Sun, C., Cai, Y., Yang, D. (2016). Hot deformation behavior of AZ80 magnesium alloy towards optimization of its hot workability, Mater. Charact., 122, pp. 90-97,

DOI: $10.1016 /$ j.matchar.2016.10.026.

[10] Chen, Q., Zhang, X., Lin, J., Zhan, H., Zhao, Z., Xie, Z., Yuan, B. (2019). Isothermal closed-die forming process of magnesium alloy upper receiver: numerical simulation and experiments, Int. J. Adv. Manuf. Technol., 102(1-4), pp. 685-694, DOI: 10.1007/s00170-018-03209-5.

[11] Gontarz, A., Dziubińska, A. (2014). Forming of flat parts with ribs from magnesium alloy, Aircr. Eng. Aerosp. Technol., 86(4), pp. 356-360, DOI: 10.1108/AEAT-10-2012-0188. 
[12] Shan, D., Xu, W., Han, X., Huang, X. (2012). Study on isothermal precision forging process of rare earth intensifying magnesium alloy, Mater. Sci. Eng. B Solid-State Mater. Adv. Technol., 177(19), pp. 1698-1702, DOI: 10.1016/j.mseb.2011.10.006.

[13] Kevorkijan, V. (2003). AZ80 and ZC71/SiC/12p closed die forgings for automotive applications: technical and economic assessment of possible mass production, Mater. Sci. Technol., 19(10), pp. 13861390, DOI: $10.1179 / 026708303225007988$.

[14] Moldovan, P., Popescu, G., Bojin, D., Constantinescu, D., Pana, M. (2009). Improving the fatigue resistance of magnesium alloys for forged parts in automotive industry, Metal. Int., 14(SPEC. ISS. 2), pp. 23-26.

[15] Lee, S.I., Lee, J.H., Park, S.H., Park, S.J., Yoon, J.H. (2016). Static strength test with as-forged controlarm in automobile with Mg-Al-Sn-Zn alloy, J. Mech. Sci. Technol., 30(8), pp. 3793-3798,

DOI: $10.1007 /$ s12206-016-0741-1.

[16] Deng, L., Ren, Z., Guo, P., Jin, J., Wang, X., Li, J. (2019). Precision forming of long-axis forgings with rib-web sections via billet optimization based on flow characteristics, Int. J. Light. Mater. Manuf., 2(2), pp. 97-106, DOI: 10.1016/j.ijlmm.2019.04.006.

[17] Yoon, J., Lee, S. (2015). Warm forging of magnesium AZ80 alloy for the control arm in an automobile, Proc. Inst. Mech. Eng. Part D J. Automob. Eng., 229(13), pp. 1732-1738,

DOI: $10.1177 / 0954407014567909$.

[18] Yoon, J., Lee, J. (2015). Process design of Warm-Forging with extruded Mg-8Al-0.5Zn alloy for differential case in automobile transmission, Int. J. Precis. Eng. Manuf., 16(4), pp. 841-846,

DOI: $10.1007 / \mathrm{s} 12541-015-0110-5$.

[19] Gryguc, A., Shaha, S.K., Behravesh, S.B., Jahed, H., Wells, M., Williams, B. (2017). Compression Behaviour of Semi-Closed Die Forged AZ80 Extrusion, Charact. Miner. Met. Mater., pp. 361-369, DOI: 10.1007/978-3-319-51382-9_39.

[20] Gryguc, A., Behravesh, S.B., Shaha, S.K., Jahed, H., Wells, M., Williams, B., Su, X. (2018). Low-cycle fatigue characterization and texture induced ratcheting behaviour of forged AZ80 Mg alloys, Int. J. Fatigue, 116, pp. 429-438, DOI: 10.1016/j.ijfatigue.2018.06.028.

[21] Gryguć, A., Behravesh, S.B., Shaha, S.K., Jahed, H., Wells, M., Williams, B., Su, X. (2019). Multiaxial cyclic behaviour of extruded and forged AZ80 Mg alloy, Int. J. Fatigue, 127, pp. 324-337,

DOI: 10.1016/j.ijfatigue.2019.06.015.

[22] Gryguć, A., Karparvarfard, S.M.H., Roostaei, A., Toscano, D., Shaha, S., Behravesh, B., Jahed, H. (2020).On the Load Multiaxiality Effect on the Cyclic Behaviour of Magnesium Alloys. Magnesium Technology 2020, pp. 151-159.

[23] Gryguc, A., Behravesh, S.B., Jahed, H., Wells, M., Williams, B., Su, X. (2020). Multiaxial Fatigue and Cracking Orientation of Forged AZ80 Magnesium Alloy, Procedia Struct. Integr., 25(1st Virtual Conference on Structural Integrity-VCSI1), pp. 486-495, DOI: 10.1016/j.prostr.2020.04.055.

[24] Kurz, G., Swiostek, J., Beaven, P.A., Letzig, D. (2018). Die Forging of Magnesium Materials, 2008(724).

[25] Gryguc, A., Jahed, H., Williams, B., McKinley, J. (2015). Magforge - Mechanical behaviour of forged AZ31B extruded magnesium in monotonic compression, Mater. Sci. Forum, 828-829, pp. 291-297, DOI: 10.4028/www.scientific.net/MSF.828-829.291.

[26] Gryguc, A., Shaha, S.K., Jahed, H., Wells, M., Williams, B., McKinley, J. (2016). Tensile and fatigue behaviour of as-forged AZ31B extrusion, Frat. Ed Integrita Strutt., 10(38), pp. 251-258,

DOI: $10.3221 /$ IGF-ESIS.38.34.

[27] Gryguć, A. (2019).Fatigue of Forged AZ80 Magnesium Alloy. University of Waterloo.

[28] Roostaei, A.A., Jahed, H. (2016). Role of loading direction on cyclic behaviour characteristics of AM30 extrusion and its fatigue damage modelling, Mater. Sci. Eng. A, 670, pp. 26-40,

DOI: 10.1016/j.msea.2016.05.116.

[29] Yu, X., Li, Y., Li, L. (2015). Fracture mechanism of AZ31 magnesium alloy processed by equal channel angular pressing comparing three point bending test and tensile test, Eng. Fail. Anal., 58, pp. 322-335, 
DOI: 10.1016/j.engfailanal.2015.04.020.

[30] Orozco-Caballero, A., Lunt, D., Robson, J.D., Quinta da Fonseca, J. (2017). How magnesium accommodates local deformation incompatibility: A high-resolution digital image correlation study, Acta Mater., 133, pp. 367-379, DOI: 10.1016/j.actamat.2017.05.040.

[31] Prasad, N.S., Naveen Kumar, N., Narasimhan, R., Suwas, S. (2015). Fracture behavior of magnesium alloys - Role of tensile twinning, Acta Mater., 94, pp. 281-293, DOI: 10.1016/j.actamat.2015.04.054.

[32] Qian, L.F.V., Roostaei, A.A., Dighrasker, U., Glinka, G., Jahed, H. (2019). Notch Plasticity and Fatigue Modelling of AZ31B-H24 Magnesium Alloy Sheet, SAE Tech. Pap. Ser., 1, pp. 1-11, DOI: $10.4271 / 2019-01-0530$.

[33] Hawryluk, M., Jakubik, J. (2016). Analysis of forging defects for selected industrial die forging processes, Eng. Fail. Anal., 59, pp. 396-409, DOI: 10.1016/j.engfailanal.2015.11.008.

[34] Shiozawa, K., Kashiwagi, T., Murai, T., Takahashi, T. (2010). Fatigue behaviour and fractography of extruded AZ80 magnesium alloys in very high cycle regime, Procedia Eng., 2(1), pp. 183-191, DOI: $10.1016 /$ j.proeng.2010.03.020.

[35] Mackie, D., Robson, J.D., Withers, P.J., Turski, M. (2015). Characterisation and modelling of defect formation in direct-chill cast AZ80 alloy, Mater. Charact., 104, pp. 116-123, DOI: $10.1016 /$ j.matchar.2015.03.033.

[36] Karparvarfard, S.M.H. (2020). Characterization and Modeling of Forged ZK60 Mg Alloys under Quasistatic and Fatigue Loadings, Univ. Waterloo, pp. 1-247.

[37] Lugo, M., Jordon, J.B., Solanki, K.N., Hector, L.G., Bernard, J.D., Luo, A.A., Horstemeyer, M.F. (2013). Role of different material processing methods on the fatigue behavior of an AZ31 magnesium alloy, Int. J. Fatigue, 52, pp. 131-143, DOI: 10.1016/j.ijfatigue.2013.02.017.

[38] Jung, K.H., Lee, S., Kim, Y.B., Ahn, B., Kim, E.Z., Lee, G.A. (2013). Assessment of ZK60A magnesium billets for forging depending on casting methods by upsetting and tomography, J. Mech. Sci. Technol., 27(10), pp. 3149-3153, DOI: 10.1007/s12206-013-0835-y.

[39] Jiang, S., Jia, Y., Wang, X. (2020). In-situ analysis of slip transfer and heterogeneous deformation in tension of Mg-5.4Gd-1.8Y-1.5Zn alloy, J. Magnes. Alloy., pp. 1-12, DOI: 10.1016/j.jma.2020.01.002. 